\title{
Is Tropical Cyclone Surge, Not Intensity, What Kills So Many People in South Asia?
}

\author{
S. NigGOL SEO \\ Muaebak Institute of Global Warming Studies, Seoul, South Korea \\ LAURA A. BAKKENSEN \\ School of Government and Public Policy, The University of Arizona, Tucson, Arizona
}

(Manuscript received 1 June 2016, in final form 7 October 2016)

\begin{abstract}
This paper statistically examines the hypothesis that the level of storm surge, not storm intensity, is primarily responsible for the large number of tropical cyclone fatalities in South Asia. Because the potential causal link between intensity and surge can confound statistical inference, the authors develop two fatality models using different assumptions on the relationship between storm surge and intensity. The authors find evidence that storm surge is a primary killer of people in South Asia relative to storm intensity. In a surgepressure independence model, it is found that a $10-\mathrm{cm}$ increase in storm surge results in a $14 \%$ increase in the number of fatalities. In a surge-pressure dependence model, a 10-cm increase in the level of surge not driven by minimum central pressure (MCP) leads to $9.9 \%$ increase in the number of fatalities. By contrast, a one-millibar $(1 \mathrm{hPa})$ decrease in $\mathrm{MCP}$ leads to a $7.3 \%$ increase in the number of fatalities, some of which is also attributable to storm surge. In South Asia, adaptation strategies should target a higher level of storm surge instead of higher-intensity storms. Policies to combat surge include permanent relocation, temporary evacuation, changes in building structures, and coastal fortification.
\end{abstract}

\section{Introduction}

One of the most feared natural disasters across South Asia is tropical cyclones (TCs). A single event can lead to catastrophic loss of life, as the 1970 Bhola cyclone killed more than 300000 people and the 1991 Bangladesh cyclone lead to more than 138000 deaths (Murty et al. 1986; Ali 1999; Sanghi et al. 2011). TC strikes often kill thousands of people and displace millions in this lowincome, densely populated region (Seo and Bakkensen 2016). Consequently, a warming planet is a major cause of concern in the South Asian region as destructive tropical cyclones are predicted by many scientists, although not all, to increase in intensity and affiliated surge height across the Indian Ocean (Elsner et al. 2008; McAdie et al. 2009; Knutson et al. 2010; Emanuel 2013; Camargo 2013; Kossin et al. 2013; Tory et al. 2013; Lin et al. 2012).

Supplemental information related to this paper is available at the Journals Online website: http://dx.doi.org/10.1175/ WCAS-D-16-0059.s1.

Corresponding author e-mail: S. Niggol Seo, niggol.seo@aya.yale.edu
Previous literature has shown that the large number of fatalities, as well as financial losses, from tropical cyclones across South Asia and the globe can be explained by hurricane intensity, frequency, storm surge, vulnerability, and adaptation capacities (Nordhaus 2010; Mendelsohn et al. 2012; Seo 2015; Seo and Bakkensen 2016). However, it remains unclear why the number of TC fatalities is so large across the Indian Ocean compared to other regions including the United States and Australia. Low income has been shown to be partly responsible for the high fatality rate in the region (Seo and Bakkensen 2016). In addition, the relative impacts of surge and intensity on TC fatalities in South Asia remain ambiguous. This is an important distinction because adaptation strategies to combat storm surge are different from those to address storm intensity.

This paper examines whether storm surge is the primary driver of a large number of tropical cyclone deaths across South Asian countries (Murty et al. 1986). This hypothesis is popular among researchers of natural disasters who are concerned with tropical cyclone impacts in this region (Ali 1999; Karim and Mimura 2008; Dube et al. 2009; Hallegatte et al. 2011; Harman et al. 2015). 
This view holds that poor, densely populated regions located in low-lying areas are extremely vulnerable to oceanic surges caused by tropical cyclones. Although people can seek a temporary shelter from high-speed winds, it is more difficult to escape from the surging seas in densely populated lowlands in poor countries.

We examine this hypothesis using the data on tropical cyclones generated in the Bay of Bengal and the Arabian Sea, including storm characteristics, associated fatalities, and socioeconomic characteristics, in order to untangle the primary cause of hurricane fatalities (Seo and Bakkensen 2016). In particular, we analyze statistically whether the primary cause of TC fatalities is storm surge and not high intensity. Because the potential causal link between intensity and surge can confound statistical inferences, we develop two fatality models driven by differing assumptions on the relationship between the level of storm surge and storm intensity: a surge-pressure independence model and a surge-pressure dependence model. The results from the empirical models are used to shed light on effective adaptation strategies for the region.

This paper is composed of six sections. Section 2 develops the theory of storm surge, intensity, and fatalities. Section 3 explains the data used for this study. Empirical results are presented in section 4 . In section 5, we describe and suggest adaptation strategies that are effective to a higher storm surge relative to those to higher storm intensity. The paper concludes with evaluations of the results and policy suggestions.

\section{Theory and models}

To estimate a fatality function of tropical cyclones using highly dispersed fatality count data, previous literature has employed a negative binomial (NB) model with explanatory variables including minimum central pressure (MCP) and income (Seo 2015; Seo and Bakkensen 2016; Bakkensen and Mendelsohn 2016). These studies find that the number of fatalities increases nonlinearly as MCP falls and decreases nonlinearly as income level rises.

These past models, however, cannot evaluate the widely held belief in the literature that storm surge, and not intensity, ${ }^{1}$ is the leading cause of death from tropical cyclones in South Asia (Murty et al. 1986; Ali 1999; Karim and Mimura 2008; Dube et al. 2009; Hallegatte et al. 2011; Harman et al. 2015). The difficulty arises

\footnotetext{
${ }^{1}$ Storm intensity is commonly expressed in units of minimum central pressure $(\mathrm{hPa})$, which is inversely related to storm intensity and fatalities.
}

because of the potential causal relationship between hurricane intensity and the level of storm surge. That is, the two variables cannot enter into the fatalities model simultaneously if the former causes the latter or vice versa. We describe these statistical problems, which are common findings from the statistics literature, in the supplemental material for interested readers.

To overcome these empirical challenges in estimating the effect of storm surge on fatalities, we develop two statistical models based on corresponding assumptions surrounding the causal relationship between storm surge and storm intensity: a surge-pressure independence model and a surge-pressure dependence model.

Note that the two models rely only on the assumptions on the relationship between storm surge and storm intensity. Hence, these models do not call for a structural calibration of a storm surge prediction model which would include many additional factors (Hubbert et al. 1991; Jelesnianski et al. 1992; Westerink et al. 1994; Woth et al. 2006; Dube et al. 2009; SURGEDAT 2015).

In our first model, we assume that minimum central pressure and surge are independent characteristics of a tropical cyclone. More specifically, we assume that the two characteristics are mostly distinct and without a causal relationship linking both variables. We call this model a surge-pressure independence model. The expected number of fatalities (FAT) from a TC is assumed to be a function of the storm intensity expressed as a function of MCP, vulnerability measures (VUL) such as income and population, and adaptation strategies (ADAPT):

$$
E\left[\mathrm{FAT}_{i}\right]=f\left(\mathrm{MCP}_{i}, \mathrm{VUL}_{i}, \mathrm{ADAPT}_{i}\right) .
$$

Assuming that FAT follows a negative binomial distribution, ${ }^{2}$ the following negative binomial regression is run in the first stage using only the MCP and vulnerability measures as explanatory variables to estimate the number of fatalities:

$$
g\left(\mu_{i}\right)=\ln \mu_{i}=\alpha+\beta_{1} \mathrm{MCP}_{i}+\gamma_{1} \mathrm{INC}_{i}+\gamma_{2} \mathrm{POP}_{i}+\varepsilon_{i},
$$

where MCP is the minimum central pressure, INC is income per capita, POP is population density, $\varepsilon_{i}$ is a white-noise error term, and $\mu$ is the mean of the negative binomial distribution of FAT from storm $i$ (Seo 2015). The log link $(g)$ ensures that the overdispersed data are adequately captured in the model and the estimated number of deaths does not become negative (Cameron

\footnotetext{
${ }^{2} \mathrm{We}$ test for, and find evidence of, overdispersion in our fatalities data.
} 
and Trivedi 1986; Lambert 1992; Hilbe 2007). The parameters are estimated using the maximum likelihood method. Given that storm surge can be separated from (i.e., orthogonal to) the MCP into the error term under the assumption we made, the parameter estimates of Eq. (2) will be unbiased.

If storm surge is a distinct characteristic of a $\mathrm{TC}$, then the residuals from the NB regression in Eq. (2) can be rewritten as follows using the storm surge:

$$
\ln \left|\hat{\varepsilon}_{i}\right|=\tilde{\alpha}+\tilde{\beta}_{1} \operatorname{SUR}_{i}+\eta_{i},
$$

where SUR is the level of storm surge (unit is $\mathrm{cm}$, as explained in the data section) and $\eta_{i}$ is a white-noise error term with zero mean.

In the above equations, $\beta_{1}$ in Eq. (2) is the constant rate of growth in TC fatality in response to a onemillibar (1 mb) increase in MCP and $\tilde{\beta}_{1}$ in Eq. (3) is the constant rate of growth in TC fatality in response to a one unit increase in storm surge. A far larger magnitude of the latter than the former would indicate that storm surge is a dominating factor in the number of deaths caused by TCs in South Asia, assuming the two units are comparable.

More formally,

$$
\begin{aligned}
& \beta_{1}=\frac{d \ln \mu_{i}}{d \mathrm{MCP}_{i}}=\frac{d \mu_{i} / \mu_{i}}{d \mathrm{MCP}_{i}}=\frac{d \mu_{i}}{d \mathrm{MCP}_{i}} / \mu_{i} . \\
& \tilde{\beta}_{1}=\frac{d \ln \left|\hat{\varepsilon}_{i}\right|}{d \mathrm{SUR}_{i}}=\frac{d\left|\hat{\varepsilon}_{i}\right|}{d \mathrm{SUR}_{i}} /\left|\hat{\varepsilon}_{i}\right| .
\end{aligned}
$$

The second model, a surge-pressure dependence model, arises from the assumption that the level of storm surge and minimum central pressure may not be independently determined. It is likely that a lower MCP leads to a higher level of storm surge (Irish et al. 2008). Literature indicates that wind and pressure are a primary factor for TC surge (Ali 1999).

In our surge-pressure dependence model, we estimate in the first stage the following linear (or nonlinear) relationship between TC surge and MCP, with $\rho_{i}$ being a white-noise error term with mean zero:

$$
\mathrm{SUR}_{i}=\tau+\phi \mathrm{MCP}_{i}+\rho_{i} .
$$

If the surge-pressure dependence model is correct, the estimate of $\phi$ will be large and significant. In addition, the adjusted $R^{2}$, a statistic of regression fit, will be high (close to 1).

The estimation of Eq. (6) allows for calculation of the residual $\hat{\rho}_{i}$, which is interpreted as any surge driven by factors orthogonal to the MCP. In other words, it is the level of storm surge that is not explained by the MCP in the regression in Eq. (6). Using this residual term, we estimate the following NB regression in the second stage:

$$
\begin{aligned}
g\left(\mu_{i}\right)= & \ln \mu_{i}=\tilde{\tau}+\tilde{\phi}_{1} \mathrm{MCP}_{i}+\varphi\left|\hat{\rho}_{i}\right|+v_{1} \mathrm{INC}_{i} \\
& +v_{2} \mathrm{POP}_{i}+\omega_{i} .
\end{aligned}
$$

In this model, the estimate of $\varphi$ will capture the effect of storm surge on the number of fatalities that is independent of the minimum central pressure. A large and significant estimate of this parameter will reveal that storm surge, and not MCP, is a dominant determinant of fatalities. If the estimate of $\varphi$ is larger than the estimate of $\left|\tilde{\phi}_{1}\right|$ given that the two marginal units are comparable, this would indicate that storm surge is, in fact, what kills so many people in South Asia.

Note that indirect effects of storm surge on TC casualties are also captured in $\left|\tilde{\phi}_{1}\right|$ because the model allows the coefficient on MCP to capture the impact of storm surge by affecting the level of the MCP.

\section{Data}

The primary source for TC-related variables is the Indian Meteorological Department (IMD), as compiled by Seo and Bakkensen (IMD 2015a,b; Seo and Bakkensen 2016). The IMD data contain information on tropical storms and cyclones generated in the north Indian Ocean-more specifically, the Bay of Bengal and the Arabian Sea-from 1990 to 2012. ${ }^{3}$

A majority of the storms made landfall on Indian coasts, but a significant number made landfall in Bangladesh, Thailand, Sri Lanka, Myanmar, Pakistan, and West African countries. This paper studies all storms making landfall in the South Asian countries and excludes storms that land in the Middle East and Africa. In Fig. 1, we shade the study area in gray, including India, Bangladesh, Myanmar, Thailand, and Sri Lanka in the Bay of Bengal, and India and Pakistan in the Arabian Sea.

The IMD maintains both the best-track data on storms and annual reports on storm activities. Information on storm characteristics come mostly from the best-track data including the spatial location of storm tracks, minimum central pressure, maximum wind speeds, and observation times (IMD 2015a). Data on the level of storm surge are not available in the best-track data and come

\footnotetext{
${ }^{3}$ This study relies on the complete 23 -yr record of tropical storms and cyclones in the Indian Ocean making landfall in our study region. Although it would be desirable to have a longer time series, a systematic record before 1990 does not exist and is of very poor quality. This period, nonetheless, does seem to capture all major long term weather and climate events in the region (Seo 2015; Seo and Bakkensen 2016)
} 

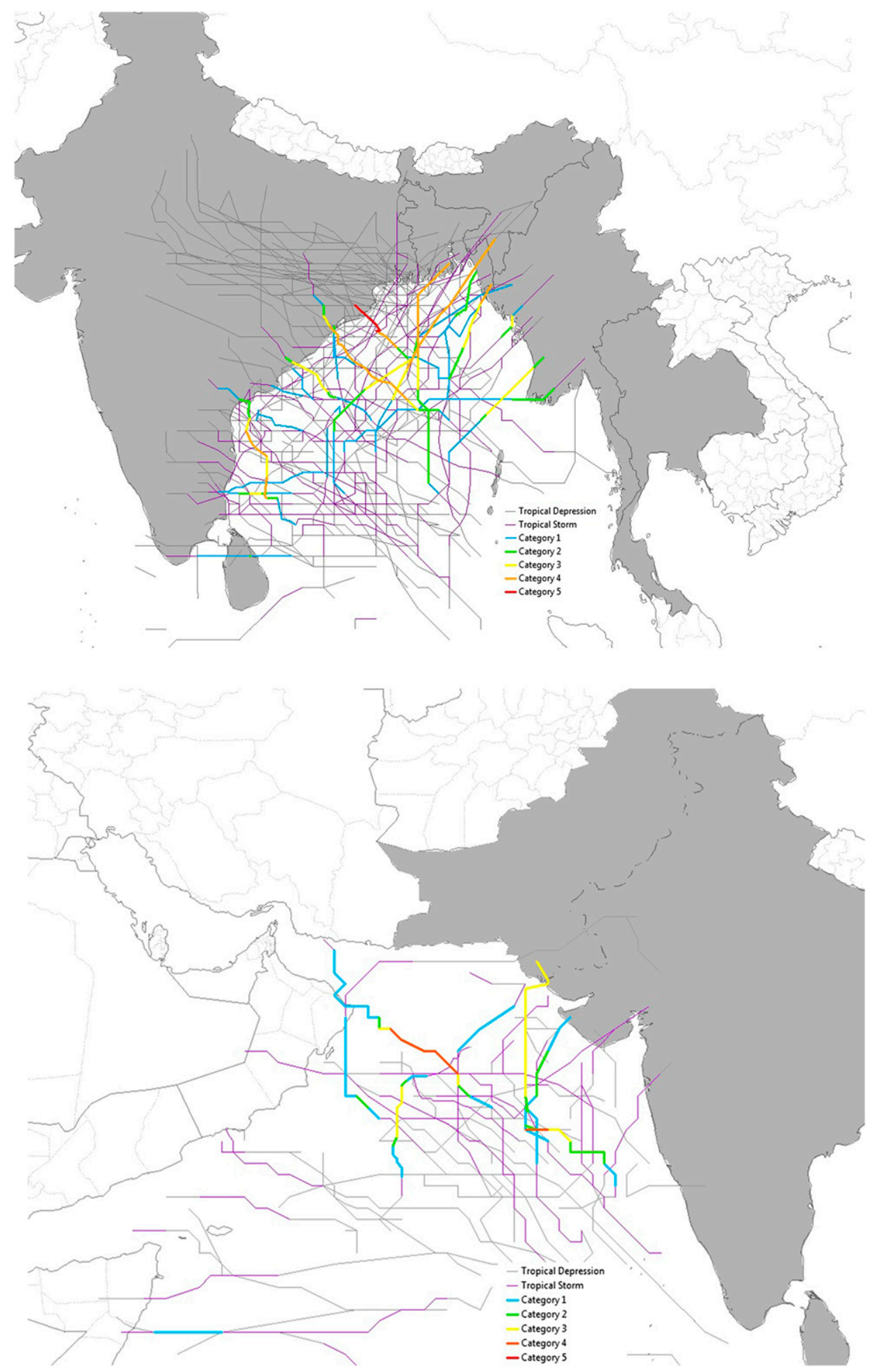

FIG. 1. Tracks of tropical storms and cyclones in the (top) Bay of Bengal and (bottom) Arabian Sea since 1990 . 
TABLE 1. Descriptive statistics.

\begin{tabular}{lrr}
\hline \hline \multicolumn{1}{c}{ Variables } & Mean & Standard deviation \\
\hline Fatalities $(N)$ & 1963.76 & 14464.79 \\
Minimum central pressure (hPa) & 987.45 & 17.78 \\
Income per capita (INR) & 17879.18 & 18838.12 \\
Population density (people per km ${ }^{2}$ ) & 537.63 & 425.92 \\
Observation interval (h) & 4.23 & 1.25 \\
Surge model (0/1) & 0.49 & 0.50 \\
Surge (m) & 0.54 & 1.36 \\
TC advisory (0/1) & 0.50 & 0.50 \\
Global Maritime Distress and Safety System (0/1) & 0.50 & 0.50 \\
Trajectory projection by Nonhydrostatic Mesoscale Model (NMM) (0/1) & 0.35 & 0.48 \\
Trajectory projection by Limited Area Model (LAM) (0/1) & 0.80 & 0.40 \\
\hline
\end{tabular}

from the annual storm reports (IMD 2015b). Information on storm damage, fatalities, and adaptation measures are also read from the annual reports.

The storm tracks, shown in Fig. 1, are mapped using information provided by the International Best Track Archive for Climate Stewardship (IBTrACS) maintained by the National Oceanic and Atmospheric Administration (NOAA) (NCEI 2016).

We obtain vulnerability indicators from the World Bank, the Open Government Data Platform of India, and government reports and statistics from other countries (World Bank 2015; Open Government Data Platform India 2015; Bangladesh Bureau of Statistics 2010, 2011; Department of Population 2014). From these sources, annual income per capita and population per $\mathrm{km}^{2}$ are obtained at the state level, considering availability of these data in the region. ${ }^{4}$ Annual regional incomes are normalized to 2006 prices using the World Bank's Consumer Price Index (CPI) and expressed in Indian rupees (INR) using market exchange rates.

\section{Empirical results}

Descriptive statistics of tropical cyclone characteristics and vulnerability variables are shown in Table 1 . On average, a tropical storm landfall in the north Indian Ocean kills about 2000 people, far higher than average fatalities per landfall in any other ocean basin in the world. The standard deviation of the number of fatalities reveals that the high average number is the result of a small number of a very high fatality TC. The most fatal TC in our dataset, which occurred in 1991, killed more than

\footnotetext{
${ }^{4}$ For countries other than India, these variables are interpolated based on the census data and historical growth rates. We also estimate the two models using country-level data from non-Indian countries and find qualitatively identical results.
}

138000 people in the region and the second most fatal TC, which occurred in 2008, killed more than 84000 people.

The MCP averages $987 \mathrm{mb}(\mathrm{hPa})$ per landfall. The average storm surge height is $54 \mathrm{~cm}$, but the standard deviation reveals that this is driven by a small number of storms with a very high surge. Storms were observed and recorded for every $4.5 \mathrm{~h}$, on average. The table also shows the statistics for the dummy variable of a computer surge prediction model, a TC advisory, the Global Maritime Distress and Safety System (GMDSS), and TC trajectory projections. As examined in the literature, these advanced technologies and international systems have been introduced to the government's TC management activities as the income level in the region has risen gradually over time (Seo and Bakkensen 2016).

During this time period, average income was about 17800 rupees per person per year (in 2006 price level), but a high standard deviation reveals that per capita income has grown rapidly since 1990 . Population density is 537 persons per $\mathrm{km}^{2}$.

In Fig. 2, we graph the relationship between storm intensity and the number of fatalities. The log of the number of fatalities increases linearly with the log of the MCP. That is, the lower the storm minimum central pressure, the higher the number of fatalities (Seo and Bakkensen 2016). It is evident from this figure that storm intensity is strongly correlated with the number of fatalities and the high-end intensity storms have resulted in exponentially large number of fatalities.

In Fig. 3, we graph the relationship between the level of storm surge and the number of fatalities. The figure shows that the log of the number of fatalities increases linearly with the level of storm surge. The higher the level of surge, the larger the number of fatalities. This figure reveals the first indication that the storm surge may be a primary killer of people during events of tropical storms and cyclones. However, Figs. 2 and 3 do not tell us which of the two TC characteristics (i.e., storm intensity or storm surge) is a dominant killer of people 


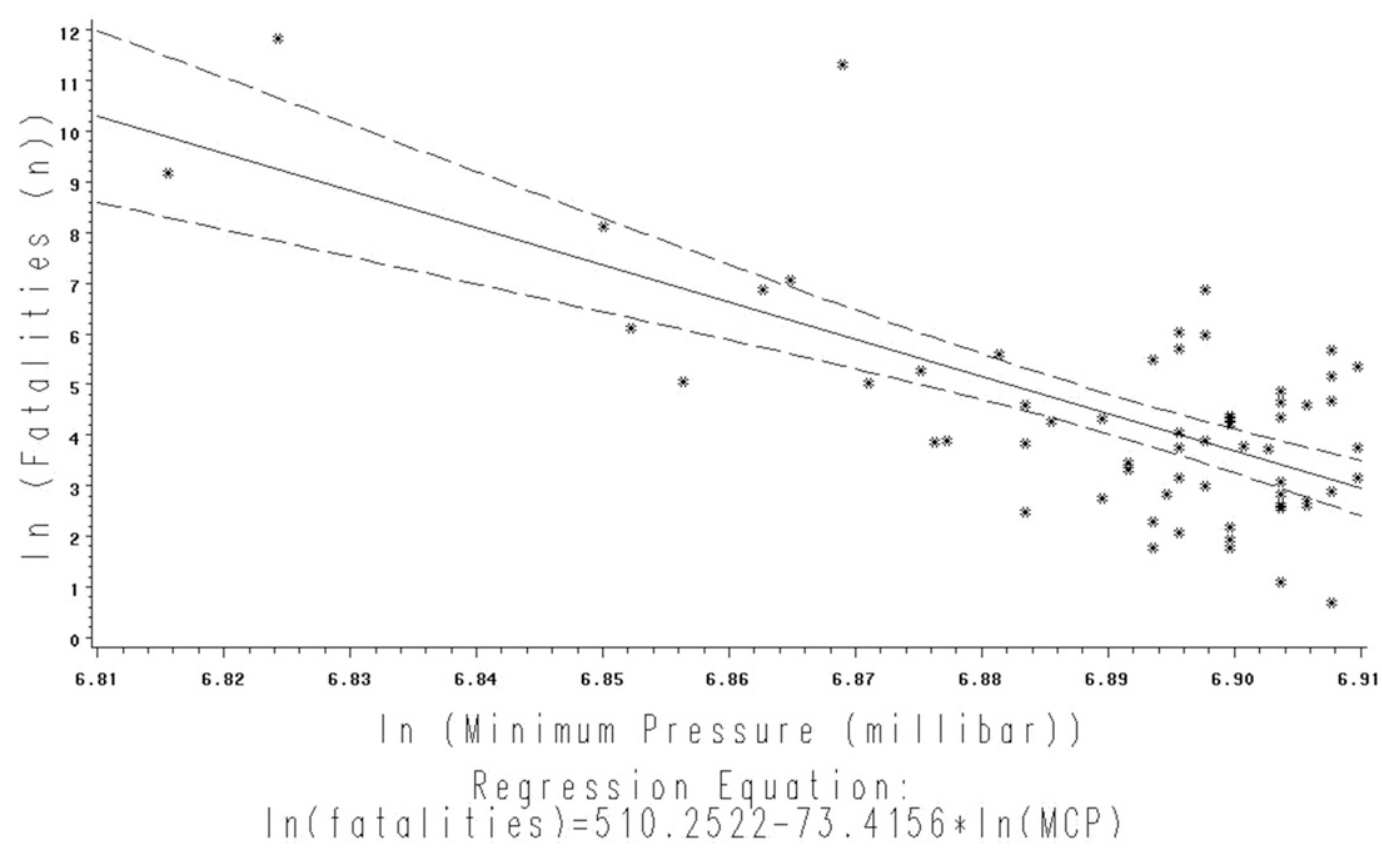

FIG. 2. Log fatalities over log minimum central pressure.

across South Asia. To answer this question, we run the two models explained in the theory section (section 2).

\section{a. A surge-pressure independence model}

In Table 2, we present results from the surge-pressure independence model described in Eqs. (1) and (2). In the first stage, a negative binomial model is run with MCP and other control variables. The model is highly significant according to the deviance and likelihood ratio statistics. The dispersion parameter is 8.3, indicating that an application of the NB model to the data is appropriate.

The parameter estimate of -0.12 for MCP tells that a 1 -mb decrease in the MCP leads to a $12 \%$ increase in the number of fatalities. The income per capita is significant

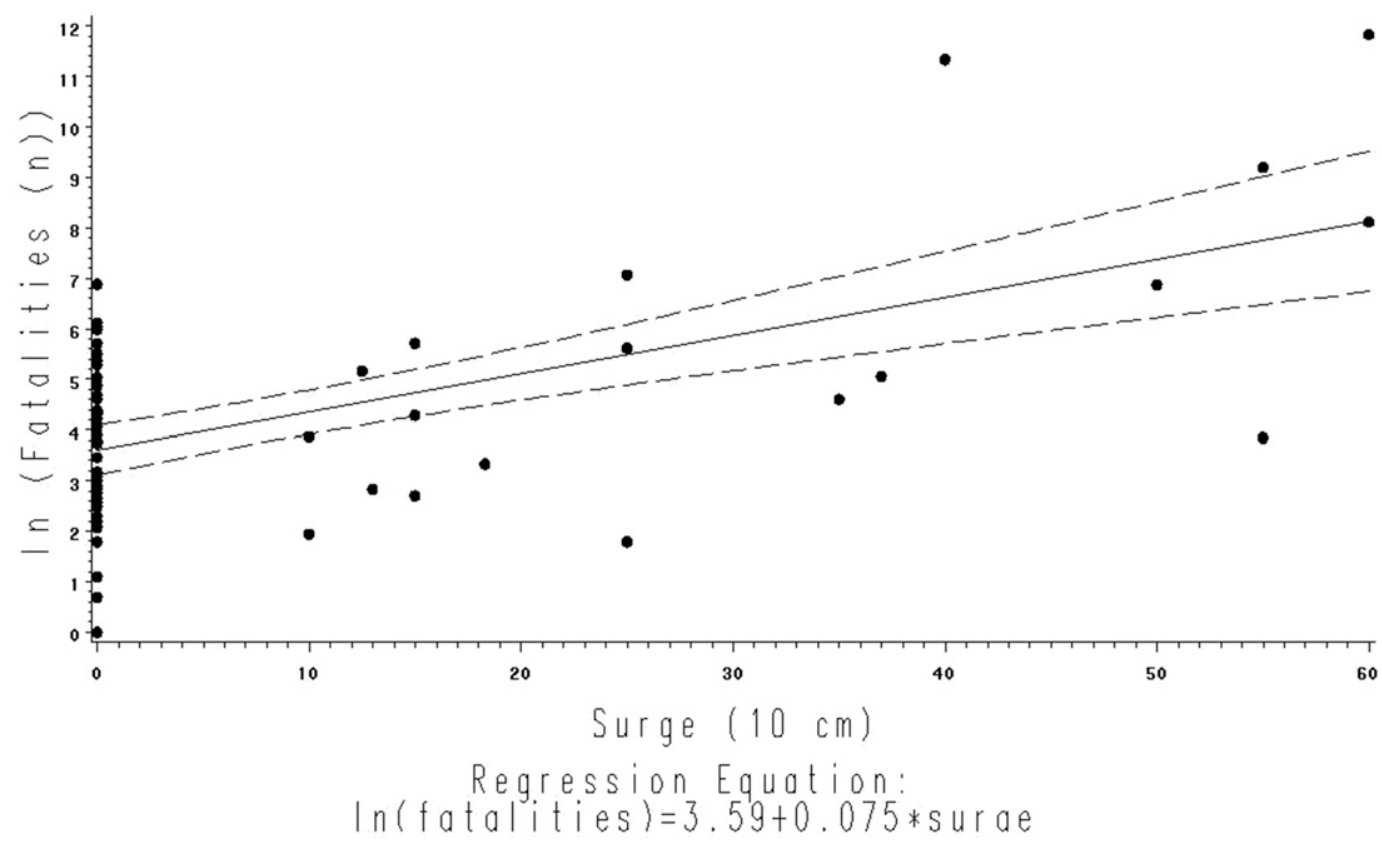

FIG. 3. Log fatalities over the level of storm surge. 
TABLE 2. A surge-pressure independence model.

\begin{tabular}{|c|c|c|c|c|c|}
\hline \multicolumn{3}{|c|}{$\begin{array}{l}\text { Stage 1: Negative binomial } \\
\text { Log (Number of fatalities) }\end{array}$} & \multicolumn{3}{|c|}{$\begin{array}{c}\text { Stage 2: Log linear } \\
\text { Residual number of fatalities from stage } 1\end{array}$} \\
\hline & Est. & $P$ value & & Est. & $P$ value \\
\hline Intercept & 124.744 & $<.0001$ & Intercept & 4.783 & $<.0001$ \\
\hline Minimum Central Pressure (hpa) & -0.121 & $<.0001$ & Surge $(\mathrm{cm})$ & 0.014 & $<.0001$ \\
\hline Income per capita (1000 INR) & -0.031 & $<.0001$ & & & \\
\hline Population density $\left(N \mathrm{~km}^{-2}\right)$ & 0.000 & 0.720 & & & \\
\hline Dispersion parameter & 8.366 & & & & \\
\hline Summary statistics & & & Summary sta & & \\
\hline Deviance (value/DF) & & 0.9701 & $F$ statistic & & $49.27(P<0.0001)$ \\
\hline Likelihood ratio & & $<0.0001$ & Adjusted $R^{2}$ & & 0.29 \\
\hline
\end{tabular}

but population density is not. A one-unit increase in income per capita (1000 INR), leads to a 3\% decrease in the number of fatalities. Population density is not significant most likely because little variation exists across population dense South Asian coasts or because an urban area with higher capabilities to cope with TC risks tends to be more populated. A no-adaptation hypothesis would assume that fatalities scale proportionately with population density, which we do not find (Bakkensen and Mendelsohn 2016).

The first-stage NB regression does not include the storm surge variable. In the second-stage NB regression, the residuals from the first-stage NB regression are regressed on storm surge. The estimate of storm surge is highly significant. The estimated surge coefficient of 0.014 shows that a $1-\mathrm{cm}$ increase in storm surge leads to a $1.4 \%$ increase in the number of deaths caused by a hurricane, which is equivalent to saying that a $10-\mathrm{cm}$ increase in the level of storm surge leads to a $14 \%$ increase in the number of fatalities.

The first- and second-stage NB regressions in the surge-pressure independence model indicate that storm surge is a major cause of death in tropical storm events. The results imply, if we can assume that storm surge and minimum central pressure are two distinct characteristics of a storm, that the two characteristics both are devastating in terms of resultant fatalities.

\section{b. A surge-pressure dependence model}

What if we assume that the storm surge and the MCP are dependent (i.e., the MCP at least partially determines the magnitude of storm surge)? A surgepressure dependence model is run in Table 3 . In the first stage, we run a linear model of the level of storm surge regressed on the $\mathrm{MCP}$, after a number of alternative specifications were tested including a log-log and a quadratic specification. The linear model is preferred based on the significance of estimates, $F$ statistic, and adjusted $R^{2}$. The model is highly significant based on comparisons of the $F$ statistic, indicating that the surgepressure dependence model should be preferred to the surge-pressure independence model.

The adjusted $R^{2}$ is 0.31 , indicating that the MCP explains $31 \%$ of the variation of the level of storm surge. This implies that the variation in the MCP explains some variation in the level of storm surge, but the rest of the total variation in the level of storm surge must be accounted for by other factors.

TABLE 3. A surge-pressure dependence model.

\begin{tabular}{|c|c|c|c|c|c|}
\hline \multicolumn{3}{|c|}{$\begin{array}{c}\text { Stage 1: Linear } \\
\text { The level of surge }(10 \mathrm{~cm})\end{array}$} & \multicolumn{3}{|c|}{$\begin{array}{l}\text { Stage 2: Negative binomial } \\
\text { Log (number of fatalities) }\end{array}$} \\
\hline & Est. & $P$ value & & Est. & $P$ value \\
\hline Intercept & 4348.405 & $<0.0001$ & Intercept & 76.7064 & $<0.0001$ \\
\hline \multirow[t]{5}{*}{ Minimum central pressure $(\mathrm{hPa})$} & -4.348 & $<0.0001$ & Minimum central pressure $(\mathrm{hPa})$ & -0.0728 & $<0.0001$ \\
\hline & & & Income per capita (1000 INR) & -0.0277 & 0.0002 \\
\hline & & & Population density $\left(N \mathrm{~km}^{-2}\right)$ & 0.0002 & 0.6985 \\
\hline & & & $\begin{array}{l}\text { Surge unexplained by MCP (Residual surge } \\
\text { from stage } 1 \text { ) }\end{array}$ & 0.0099 & $<0.0001$ \\
\hline & & & Dispersion parameter & 7.6312 & \\
\hline Summary statistics & & & Summary statistics & & \\
\hline$F$ value & 57.53 & $<0.0001$ & Deviance (Val/DF) & & 0.979 \\
\hline Adjusted $R^{2}$ & 0.31 & & Likelihood ratio ( $P$ value $)$ & & $<0.0001$ \\
\hline
\end{tabular}


The parameter estimate of -4.34 for the MCP shows that a $1-\mathrm{mb}(1 \mathrm{hPa})$ decrease in the MCP leads to a $4.34-\mathrm{cm}$ increase in the height of storm surge. This implies that a $10-\mathrm{mb}$ decrease in the MCP would lead to an average $43.4-\mathrm{cm}$ increase in the height of storm surge. The estimate is highly significant.

From the first-stage regression in Table 3, we construct a variable of storm surge that is orthogonal to the MCP using the residuals in the first-stage regression. This variable can be seen as the surge variable independent of (i.e., not explained by) the storm intensity.

In the second stage, we estimate an NB regression of the number of fatalities using both the MCP and the MCP-cleaned surge variable plus other controls. The NB regression is highly significant according to the deviance and likelihood ratio statistics. In addition, the parameter estimates for both the MCP and the unexplained residual surge are highly significant. The dispersion parameter is 7.6.

The parameter estimates are notable in several ways. First, the estimate of the MCP is -0.07 . This is a much smaller sensitivity than the -0.12 in the first-stage regression of the surge-pressure independence model, which is probably because the surge effect independent of TC intensity is explicitly separated out in the surge-pressure dependence model. It means that a $1-\mathrm{mb}$ decrease in the MCP leads to $7 \%$ increase in the number of fatalities, instead of $12 \%$ increase in the regression with the variable of surge level omitted. This again means that the surgepressure independence model would overestimate the impacts of both the MCP and the storm surge on fatalities because of the causal relationship between the variables.

Second, the income parameter is -0.028 . This is consistent with the estimate of income sensitivity by Seo and Bakkensen (2016). A 1000-rupee increase in income per capita leads to $2.8 \%$ decrease in the number of fatalities. The estimate of population density is positive, but again not significant.

Third, the estimate of the residual (unexplained) surge is 0.0099 . This means that a $10-\mathrm{cm}$ increase in the level of surge which does not depend on the MCP leads to $9.9 \%$ increase in the number of fatalities. This is the most important finding of this paper, supporting the popular claim that a high surge is what mostly kills so many people in South Asian countries. The $9.9 \%$ increase in the number of deaths caused by the increase in storm surge unexplained by the MCP is much larger than the 7\% increase caused by the decrease in the MCP. Further, since the MCP and the surge are causally dependent as shown in the first stage of the model, the $7 \%$ sensitivity can be in part ascribed to the effect of a higher surge.

Thus, we find the evidence that storm surge is a predominant cause of fatalities from tropical storms and cyclones in South Asia. The results imply that both storm intensity and storm surge are responsible for a large number of deaths, but storm surge is more devastating than storm intensity in South Asia.

\section{Adaptation strategies to storm surges}

The predominance of storm surge among factors that cause tropical storm fatalities in South Asian nations has strong policy and behavioral implications (Ali 1999; Harman et al. 2015). Adaptation strategies must respond to a high storm surge rather than solely to high storm intensity, as the latter may turn out to be ineffective, or even risk-inducing, in response to a high surge.

What are effective adaptation strategies to a storm surge? We review general strategies here, including permanent relocation, temporary evacuation, zoning and building codes, physical barriers, and considerations of post-disaster assistance. However, this is not meant to be an exhaustive list and we note that the most effective strategies will vary across locations depending upon local socioeconomic and cyclone characteristics, as well as policy objectives.

Permanent relocation of people or retreat from lowlying coastal zones can ensure that individuals are out of harm's way. However, because of high population density and lack of governmental resources in South Asian countries, it may not be always feasible (Ali 1999). Further, permanent relocation would mean leaving a traditional way of life culturally important for these communities. For example, people have populated hazard-prone low-lying zones such as the Ganges-Brahmaputra delta for centuries because the river delta is fertile for rice and jute productions (Sanghi et al. 2011).

Temporary evacuation of vulnerable communities preceding storm events can be effective at reducing fatalities if warning information is disseminated early and individuals have the ability to temporarily migrate to safer land. An early warning system in cooperation with the international hurricane agencies and aided by tropical storm projection techniques, as shown in Table 1 , can play a pivotal role in making evacuation decisions.

Increasing the stringency of building codes can increase the number of built dwellings that are more physically resilient against a storm surge. For example, a multistory apartment complex or raised stilted or piloti structures can give residents a place to escape from a surge and flooding.

In addition, sea walls and polders can prevent or reduce the intensity by which seawater inundates coastal communities. However, the cost of building and maintaining sea walls can be significant. Green buffers, such 
as mangrove forests, can provide partial protection from storm surges. However, unintended spillover impacts from adaptation can occur. For example, tourism may significantly suffer if sea walls are built along the beaches (Ng and Mendelsohn 2006).

Last, policy makers need to consider the provision of health services, food, sanitation, and water during and after a storm surge event. Mental health issues, such as post-traumatic stress disorder, can be prevalent after a deadly surge event (Shultz et al. 2005).

Two currently utilized strategies in Bangladesh that have been effective at reducing fatalities include storm shelters and polders. The country began its public cyclone shelter program in 1972 (Paul 2009). When Tropical Cyclone Sidr made landfall in 2007, almost 4000 shelters across 15 coastal districts helped protect lives. The distance between shelters is sometimes as long as $5.6 \mathrm{~km}$, making it difficult for people to evacuate in time without enough advance warning. However, given the high value of statistical life, even in low-income countries, the evacuation strategy is likely to be cost effective (Bowland and Beghin 2001; Miller 2000). In addition, Bangladesh began employing polders to decrease wave energy in coastal areas in the 1960s and 1970s (Huq et al. 2010). However, with the sea level rises caused by climate changes, it is unclear how soon these polders may become overtopped and ineffective.

Which of these various adaptation strategies should be preferred by an individual or a community? A set of adaptation strategies should depend on the unique characteristics of the coastal community and the tropical storm events in consideration. Permanent relocation may be preferred for a community that is hit very frequently by a high storm surge event. A community that is not frequently hit by storm surge may prefer temporary evacuation of its residents. A community with valuable resources on the coastal zone may prefer renovating and reconstructing its buildings. A community with fertile lands and high population may prefer a sea wall or polder along the coast. Each location must consider the costs and benefits of adaptation, as well as their policy objectives.

\section{Conclusions}

This paper statistically examines the hypothesis that the level of storm surge, not the intensity of a storm, is primarily responsible for the large numbers of fatalities in South Asia caused by tropical cyclones. We develop two statistical models to test the hypothesis: a surgepressure independence model and a surge-pressure dependence model. We find evidence that storm surge is a primary killer of people during storm events while storm intensity is a secondary killer.
A surge-pressure independence model finds that a large number of fatalities that are not explained by the minimum central pressure (MCP) are explained by the level of storm surge: a $10-\mathrm{cm}$ increase in storm surge increases the number of fatalities by $14 \%$. A surgepressure dependence model finds that the level of storm surge is partly explained by the MCP. The level of storm surge that is not explained by the MCP accounts for the large number of fatalities: a $10-\mathrm{cm}$ increase in the level of storm surge unexplained by the MCP leads to a $9.9 \%$ increase in the number of fatalities. By contrast, a 1-mb decrease in the MCP leads to a $7 \%$ increase in the number of fatalities. In addition, some of the $7 \%$ increase in the number of fatalities due to the MCP is attributable to a higher level of surge.

These results have strong policy and behavioral implications with regards to tropical storms and cyclones in a gradually warming world. Adaptation strategies that were designed to withstand high-intensity cyclones such as shelters and bunkers may turn out to be ineffective against high-surge cyclones and storms. Adaptation strategies should rather be designed to target a higher level of storm surge. The choice should be made by considering the benefits and costs of available options such as permanent relocation, temporary evacuation, changes in housing and building structures, and building a sea wall or a polder.

We conclude the paper with a few qualifications. First, it would be meaningful to estimate the numbers of future fatalities due to changes in tropical cyclones as was done by Seo and Bakkensen (2016). However, a future projection of the level of storm surge is not available as of yet (Emanuel 2008; Dube et al. 2009; Knutson et al. 2010; IPCC 2013). Future fatality predictions in South Asia made by Seo and Bakkensen are mostly applicable to this paper with some modifications. Second, the data on the levels of storm surge provided by the Indian Bureau of Meteorology are not perfect in terms of both data collection methods and observations. Further, the quality of historical data on subnational income may not be high in this poor region. However, we believe that the data are sufficiently meaningful to draw a conclusion on the question posed in this paper. Third, it is unclear how, or to what extent, a future storm surge may be impacted additionally by regional sea level rises caused by climate change, or how these impacts will be realized in South Asia (Ali 1999; Woth et al. 2006; Karim and Mimura 2008; Frazier et al. 2010).

Acknowledgments. We thank the editor and anonymous reviewers for helpful comments. No funding was received for this research. 


\section{REFERENCES}

Ali, A., 1999: Climate change impacts and adaptation assessment in Bangladesh. Climate Res., 12, 109-116, doi:10.3354/cr012109.

Bakkensen, L. A., and R. Mendelsohn, 2016: Risk and adaptation: Evidence from global hurricane damages and fatalities. J. Assoc. Environ. Resour. Econ., 3, 555-587, doi:10.1086/685908.

Bangladesh Bureau of Statistics, 2010: Report of household income and expenditure survey 2010. Ministry of Planning, Government of Bangladesh, accessed November 2016. [Available online at http://catalog.ihsn.org/index.php/catalog/2257.]

_- 2011: Population and housing census 2011: Socio-economic and demographic report. Ministry of Planning, Government of Bangladesh, accessed November 2016. [Available online at http://catalog.ihsn.org/index.php/catalog/4376.]

Bowland, B. J., and J. C. Beghin, 2001: Robust estimates of value of a statistical life for developing economies. J. Policy Model., 23, 385-396, doi:10.1016/S0161-8938(01)00072-2.

Camargo, S. J., 2013: Global and regional aspects of tropical cyclone activity in the CMIP5 models. J. Climate, 26, 9880-9902, doi:10.1175/JCLI-D-12-00549.1.

Cameron, A. C., and P. K. Trivedi, 1986: Econometric models based on count data: Comparisons and applications of some estimators and some tests. J. Appl. Econ., 1, 29-53, doi:10.1002/ jae.3950010104.

Department of Population, 2014: The 2014 Myanmar population and housing census. DOP, Ministry of Immigration and Population, Government of Myanmar, accessed November 2016. [Available online at http://www.dop.gov.mm/moip/ index.php?route $=$ product $/$ product $\&$ product_id $=140$.]

Dube, S. K., I. Jain, A. D. Rao, and T. S. Murty, 2009: Storm surge modelling for the Bay of Bengal and Arabian Sea. Nat. Hazards, 51, 3-27, doi:10.1007/s11069-009-9397-9.

Elsner, J. B., J. P. Kossin, and T. H. Jagger, 2008: The increasing intensity of the strongest tropical cyclones. Nature, 455, 92-95, doi:10.1038/nature07234.

Emanuel, K., 2008: The hurricane-climate connection. Bull. Amer. Meteor. Soc., 89, ES10-ES20, doi:10.1175/BAMS-89-5-Emanuel.

, 2013: Downscaling CMIP5 climate models shows increased tropical cyclone activity over the 21st century. Proc. Natl. Acad. Sci. USA, 110, 12219-12 224, doi:10.1073/pnas.1301293110.

Frazier, T. G., N. Wood, B. Yarnal, and D. H. Bauer, 2010: Influence of potential sea level rise on societal vulnerability to hurricane storm-surge hazards, Sarasota County, Florida. Appl. Geogr., 30, 490-505, doi:10.1016/j.apgeog.2010.05.005.

Hallegatte, S., N. Ranger, O. Mestre, P. Dumas, J. Corfee-Morlot, C. Herweijer, and R. M. Wood, 2011: Assessing climate change impacts, sea level rise and storm surge risk in port cities: A case study on Copenhagen. Climatic Change, 104, 113-137, doi:10.1007/s10584-010-9978-3.

Harman, B. P., S. Heyenga, B. M. Taylor, and C. S. Fletcher, 2015: Global lessons for adapting coastal communities to protect against storm surge inundation. J. Coast. Res., 31, 790-801, doi:10.2112/JCOASTRES-D-13-00095.1.

Hilbe, J. M., 2007: Negative Binomial Regression. Cambridge University Press, $251 \mathrm{pp}$.

Hubbert, G. D., G. J. Holland, L. M. Leslie, and M. J. Manton, 1991: A real-time system for forecasting tropical cyclone storm surges. Wea. Forecasting, 6, 86-97, doi:10.1175/ 1520-0434(1991)006<0086:ARTSFF > 2.0.CO;2.

Huq, M., M. F. Khan, K. Pandey, M. M. Z. Ahmed, Z. H. Khan, S. Dasgupta, and N. Mukherjee, 2010: Vulnerability of Bangladesh to cyclones in a changing climate: Potential damages and adaptation cost. World Bank Policy Research Working Paper 5280, 54 pp., doi:10.1596/1813-9450-5280.

India Meteorological Department, 2015a: Reports on cyclonic disturbances in north Indian Ocean from 1990 to 2012. Regional Specialised Meteorological Centre-Tropical Cyclones, New Delhi, accessed November 2016. [Available online at http://www.rsmcnewdelhi.imd.gov.in/index.php?option $=$ com content $\&$ view $=$ article $\&$ id $=30 \&$ Itemid $=176 \&$ lang $=$ en. $]$

_ 2015b: Best track data of tropical cyclonic disturbances over the north Indian Ocean Regional Specialised Meteorological Centre-Tropical Cyclones, New Delhi, accessed November 2016. [Available at http://www.rsmcnewdelhi.imd. gov.in/index.php?option $=$ com_content $\&$ view $=$ article $\&$ id $=$ 48\&Itemid=194\&lang =en. Accessed on November 2016.]

IPCC, 2013: Climate Change 2013: The Physical Science Basis. T. F. Stocker et al., Eds., Cambridge University Press, 1535 pp.

Irish, J. L., D. T. Resio, and J. J. Ratcliff, 2008: The influence of storm size on hurricane surge. J. Phys. Oceanogr., 38, 20032013, doi:10.1175/2008JPO3727.1.

Jelesnianski, C. P., J. Chen, and W. A. Shaffer, 1992: SLOSH: Sea, Lake, and Overland Surges from Hurricanes. NOAA Tech. Rep. NWS 48, 71 pp. [Available online at slosh.nws.noaa.gov/ sloshPub/pubs/SLOSH_TR48.pdf.]

Karim, M. F., and N. Mimura, 2008: Impacts of climate change and sea-level rise on cyclonic storm surge floods in Bangladesh. Global Environ. Change, 18, 490-500, doi:10.1016/ j.gloenvcha.2008.05.002.

Knutson, T. R., and Coauthors, 2010: Tropical cyclones and climate change. Nat. Geosci., 3, 157-163, doi:10.1038/ngeo779.

Kossin, J. P., T. L. Olander, and K. R. Knapp, 2013: Trend analysis with a new global record of tropical cyclone intensity. J. Climate, 26, 9960-9976, doi:10.1175/JCLI-D-13-00262.1.

Lambert, D., 1992: Zero-inflated Poisson regression, with an application to defects in manufacturing. Technometrics, 34, 1-14, doi:10.2307/1269547.

Lin, N., K. Emanuel, M. Oppenheimer, and E. Vanmarcke, 2012: Physically based assessment of hurricane surge threat under climate change. Nat. Climate Change, 2, 462-467, doi:10.1038/ nclimate1389.

McAdie, C. J., C. W. Landsea, C. J. Neuman, J. E. David, E. Blake, and G. R. Hamner, 2009: Tropical Cyclones of the North Atlantic Ocean, 1851-2006. Historical Climatology Series 6-2, National Climatic Data Center, 238 pp.

Mendelsohn, R., K. Emanuel, S. Chonabayashi, and L. Bakkenshen, 2012: The impact of climate change on global tropical cyclone damage. Nat. Climate Change, 2, 205-209, doi:10.1038/ nclimate1357.

Miller, T. R., 2000: Variations between countries in values of statistical life. J. Transp. Econ. Policy, 34, 169-188.

Murty, T. S., R. A. Flather, and R. F. Henry, 1986: The storm surge problem in the Bay of Bengal. Prog. Oceanogr., 16, 195-233, doi:10.1016/0079-6611(86)90039-X.

NCEI, 2016: International Best Track Archive for Climate Stewardship. National Centers for Environmental Information and National Oceanic and Atmospheric Administration (NOAA). Accessed November 2016. [Available online at https://www. ncdc.noaa.gov/ibtracs/.]

$\mathrm{Ng}$, W. S., and R. Mendelsohn, 2006: The economic impact of sealevel rise on nonmarket lands in Singapore. Ambio, 35, 289296, doi:10.1579/05-A-076.1.

Nordhaus, W., 2010: The economics of hurricanes and implications of global warming. Climate Change Econ., 1, 1-24, doi:10.1142/ S2010007810000054. 
Open Government Data Platform India, 2015: Per capita net state domestic product at current prices. Government of India, New Delhi, accessed November 2016. [Available online at https://data.gov.in/catalog/capita-net-state-domesticproduct-current-prices.]

Paul, B. K., 2009: Why relatively fewer people died? The case of Bangladesh's Cyclone Sidr. Nat. Hazards, 50, 289-304, doi:10.1007/s11069-008-9340-5.

Sanghi, A., S. Ramachandran, A. de la Fuente, M. Tonizzo, S. Sahin, and B. Adam, 2011: Natural Hazards, Unnatural Disasters: The Economics of Effective Prevention. World Bank Group, $276 \mathrm{pp}$.

Seo, S. N., 2015: Fatalities of neglect: Adapt to more intense hurricanes? Int. J. Climatol., 35, 3505-3514, doi:10.1002/ joc. 4224 .

— High fatalities from tropical cyclones in the North Indian Ocean and future vulnerability under global warming. Nat. Hazards, 82, 1341-1355, doi:10.1007/s11069-016-2250-z.

Shultz, J. M., J. Russell, and Z. Espinel, 2005: Epidemiology of tropical cyclones: The dynamics of disaster, disease, and development. Epidemiol. Rev., 27, 21-35, doi:10.1093/epirev/mxi011.
SURGEDAT, 2015: Global peak surge map. SURGEDAT: The World's Surge Data Center, Louisiana State University. Accessed November 2016. [Available online at http://surge.srcc. lsu.edu/data.html\#GlobalMap.]

Tory, K. J., S. S. Chand, J. L. McBride, H. Ye, and R. A. Dare, 2013: Projected changes in late-twenty-first-century tropical cyclone frequency in 13 coupled climate models from phase 5 of the Coupled Model Intercomparison Project. J. Climate, 26, 99469959, doi:10.1175/JCLI-D-13-00010.1.

Westerink, J. J., C. A. Blain, R. A. Luettich, and N. W. Scheffner, 1994: ADCIRC: An Advanced Three-Dimensional Circulation Model for Shelves, Coasts and Estuaries; Report 2: Users' Manual for ADCIRC-2DDI. Dredging Research Program Technical Report DRP-92-6, U.S. Army Engineers Waterways Experiment Station, Vicksburg, MS., 156 pp.

World Bank, 2015: India. Accessed November 2016. [Available online at http://data.worldbank.org/country/india.]

Woth, K., R. Weisse, and H. Von Storch, 2006: Climate change and North Sea storm surge extremes: An ensemble study of storm surge extremes expected in a changed climate projected by four different regional climate models. Ocean Dyn., 56, 3-15, doi:10.1007/s10236-005-0024-3. 